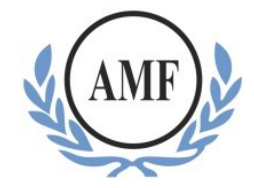

\title{
Passagens de valor para uma cidadania global: a formação humanista de uma inteligência superior e o consequente alcance de um direito fundamental em consonância com os valores das Nações Unidas
}

\author{
Daiane Dutra Rieder ${ }^{1}$ \\ Mateus Renard Machado ${ }^{2}$
}

\begin{abstract}
Resumo: A palavra educação não mais se restringe a um simples processo pedagógico nos dias atuais. É necessário o implemento de valores substanciais que façam emergir uma inteligência superior. E esse é o modo pelo qual a Antonio Meneghetti Faculdade (AMF), pautada nos princípios da Ciência Ontopsicológica, como também em propostas da Organização das Nações Unidas, forma, hoje, cidadãos de uma consciência global, capazes de serem gestores de impactos na sociedade em que vivem. Por meio das atividades propostas, a AMF ainda se consolida como uma instituição privada que norteia a garantia de um direito fundamental, inerente à pessoa humana: o direito à educação. Mediante a aplicação da metodologia bibliográfica, este trabalho substancia-se a partir de uma discussão teórica acerca de dois valores principais - o humanismo e a sustentabilidade -, trabalhados constantemente na instituição como valores substanciais para o desenvolvimento integral do ser humano e, consequentemente, do social.
\end{abstract}

Palavras-chave: Pedagogia Ontopsicológica. Organização das Nações Unidas. Sustentabilidade. Humanismo. Cidadania global.

Passages of value for a global citizenship: the humanist trainning of a higher intelligence and the consequent reach of a fundamental right in accordance with the values of the United Nations

\begin{abstract}
The word education is no longer restricted to a simple pedagogical process in these days. It is necessary to implement substantial values that emerge a superior intelligence. And this is the way in which the Antonio Meneghetti Faculdade (AMF), based on the principles of the Ontopsychological Science, as well as in proposals of the United Nations, forms, today, citizens of a global conscience, capable of being managers of impacts in the society in which they live. Through the proposed activities, AMF is also consolidated as a private institution that guides the guarantee of a fundamental right, inherent to the human person: the right to education. Through the application of a bibliographical methodology, this work is substantiated by a theoretical discussion about two main values - humanism and sustainability - constantly worked in the institution as substantial values for the integral development of the human being and, consequently, of the social.

Keywords: Ontopsychological Pedagogy. United Nations Organization. Sustainability. Humanism. Global citizenship.
\end{abstract}

\footnotetext{
${ }^{1}$ Acadêmica do quarto semestre do curso Bacharelado em Direito da Antonio Meneghetti Faculdade (AMF), juntamente à Università Degli Studi di Torino (UniTo). Acadêmica do segundo módulo do curso Bacharelado em Ontopsicologia da Antonio Meneghetti Faculdade (AMF).

${ }^{2}$ Mestre em Filosofia (UFSM), advogado, professor de Filosofia e Lógica dos cursos de Direito e Ontopsicologia da Antonio Meneghetti Faculdade (AMF). Coordena o Grupo de Estudos em Ética e Teoria da Justiça - GEETJ. Realiza pesquisas em Ética, Teorias Contemporâneas da Justiça, Teoria Sistêmica, Niklas Luhmann.
} 
Pasos de valor para una ciudadanía global: la formación humanista de una inteligencia superior $y$ el consecuente alcance de un derecho fundamental en consonancia con los valores de las Naciones Unidas

Resumen: La palabra educación ya no se restringe a un simple proceso pedagógico en los días actuales. Es necesario el implemento de valores sustanciales que hagan emerger una inteligencia superior. Y ese es el modo en que Antonio Meneghetti Facultad (AMF), pautada en los principios de la Ciencia Ontopsicológica, así como en propuestas de la Organización de las Naciones Unidas, forma, hoy, ciudadanos con una conciencia global, capaces de ser gestores de impactos en la sociedad en que viven. Por medio de las actividades propuestas, la AMF aún se consolida como una institución privada que orienta la garantía de un derecho fundamental, inherente a la persona humana: el derecho a la educación. A través de la aplicación de la metodología bibliográfica, este trabajo se sustenta a partir de una discusión teórica acerca de dos valores principales - el humanismo y la sostenibilidad - trabajados constantemente en la institución como valores sustanciales para el desarrollo integral del ser humano y, consecuentemente, del social.

Palabras clave: Pedagogía Ontopsicológica. Organización de las Naciones Unidas. Sostenibilidad. Humanismo. Ciudadanía global.

\section{Introdução}

A aurora da palavra "educação" faz referência ao termo latino "educare" (MICHAELIS, 2018), que se remete ao ato da condução do conhecimento (SCOTTINI, 2009, p. 220) para o externo, ou seja, para o outro. Transmitir conhecimentos com o intuito de desenvolver outras inteligências e a si mesmo é, portanto, o início de uma consciência de caráter extrínseco, que vai ao encontro de um bem maior: o desenvolvimento social. E pautar a consciência como capacidade de natureza intelectual e emocional que o ser humano tem de considerar, ou reconhecer, a realidade exterior (MICHAELIS, 2018), conecta-se a esse desenvolvimento.

Identificar esses dois aspectos, educação e consciência, fez-nos pensar em correlacionar a metodologia abrangida pela escola de Pedagogia Ontopsicológica, enquanto norteadora de uma formação humanista, às temáticas desenvolvidas pelas Nações Unidas, em seus 73 anos de atuação, enquanto um vetor de desenvolvimento social. E é a partir desta união que a Antônio Meneghetti Faculdade (AMF) forma, hoje, jovens e adultos aptos a usufruírem de uma formação interdisciplinar, ou seja, de uma arte de educar que reúne o desenvolvimento do homem à uma ação prática de valor, não deixando de lado o consequente alcance de direitos fundamentais inerentes à pessoa humana. 


\section{Fundamentação teórica}

2.1 A arte de educar como sinônimo de desenvolvimento humano e social: a escola de Pedagogia Ontopsicológica e o resgate de valores pautados pelas Nações Unidas

Os valores institucionais de interdisciplinaridade concretizados na Antonio Meneghetti Faculdade (AMF) estão alicerçados na formação integral do homem. Toda a vivência acadêmica é realizada por meio de uma formação que viabiliza a experiência em sua totalidade, com conhecimentos em diferentes campos do saber, perspectivas teóricas e práticas variadas (AMF, 2018).

Em meio a estas conceituações, a aderência de estudos e práticas no campo do humanismo e da sustentabilidade faz referência às propostas de trabalho das Nações Unidas, de modo que conceituar o papel da educação no desenvolvimento do homem, e no consequente desenvolvimento do social, seja um vetor para mudanças significativas e abrangentes frente a um contexto maior: o alcance de direitos fundamentais.

$\mathrm{Na}$ consecução de uma educação ímpar e que seja portadora de resultados significativos frente ao ambiente social, é importante ressaltar o implemento de atividades que se conduzem ao encontro de compromissos que fazem referência aos 17 Objetivos de Desenvolvimento Sustentável (ODS), propostos pela Organização das Nações Unidas, com o objetivo de pautar ações que vão ao encontro de um caminho mais próspero e sustentável para as atuais e futuras gerações.

Dentre os 17 objetivos globais - outra nominação com a qual podemos nos referir aos ODS -, a Antonio Meneghetti Faculdade executa, de modo claro, o objetivo de número quatro, o qual dispõe sobre "assegurar a educação inclusiva e equitativa e de qualidade, e promover oportunidades de aprendizagem ao longo da vida para todas e todos" (NAÇÕES UNIDAS, 2018). Ou seja, podemos retratar a proposta central dos ofícios desenvolvidos na instituição de ensino superior posta em análise a partir do desenvolvimento de uma educação que faça jus a um aprendizado superior e de grande abrangência social, conforme proposto pelas Nações Unidas.

A Organização das Nações Unidas possui uma agência especializada nas áreas de Educação, Ciência e Cultura, que é assim denominada e já conhecida mundialmente: a UNESCO. Seus trabalhos fazem referência ao cumprimento de metas globais que primam por uma sociedade de caráter igualitário e justo. Neste sentido: 
Todo o ser humano deve ser preparado, especialmente graças à educação que recebe na juventude, para elaborar pensamentos autônomos e críticos e para formular os seus próprios juízos de valor, de modo a poder decidir, por si mesmo, como agir nas diferentes circunstâncias da vida (DELLORS, p. 99).

Tal passagem remete-nos a pensar acerca do modo em que a AMF desenvolve suas atividades: a educação não é proposta somente como uma contínua partilha e consequente aquisição de conhecimentos, mas ela é considerada um alicerce constante no desenvolvimento do ser humano (ABO, 2011, p. 22), em que é necessária a aquisição de valores pontuais para que seja promovido, em modo pleno, um desenvolvimento humano integral. E, conforme exposto na citação acima elencada, somente desta maneira se conseguirá possuir a formação de jovens que tenham a capacidade de uma ação prática que gere impactos na sociedade em se que vive.

Entrando no mérito dos valores, a Antonio Meneghetti Faculdade aprecia o resgate da cultura humanista em seus ensinamentos. Propõe ao jovem a ideia de que a oportunidade e a responsabilidade de ser instrumento de real serviço à sociedade, bem como um meio de viabilizar o desenvolvimento sustentável (ABO, 2011, p. 47), são méritos possíveis de serem alcançados, pois ele, enquanto humano, é um agente protagonista, é um sujeito-ator do desenvolvimento. Faz-se, portanto, interessante ressaltar uma entrevista realizada com o Dr. Vicent Defourny, sobre o humanismo, em que esse é evidenciado como

\begin{abstract}
[...] um elemento que existe desde a antiguidade, desde que o homem é homem. Faz parte da humanidade a necessidade de trabalhar e de desenvolver valores, mas valores humanistas, valores que dão uma certa centralidade no humano. As Nações Unidas, no momento em que elaboraram a Declaração Universal dos Direitos Humanos, que é fundamentada por uma visão humanista, colocaram o homem e os valores humanistas no centro. Ao mesmo tempo, no seu projeto de cooperação internacional, colocam as dimensões culturais e a variedade das culturas como elementos fundamentais a serem incorporados e a serem levados em consideração no diálogo entre as várias civilizações, culturas e pessoas. Um certo tipo de humanismo tem que ser resgatado, e os elementos centrais são aqueles que colocam o sujeito como ator do desenvolvimento individual e coletivo (ABO, 2011, pp. 28-29).
\end{abstract}

À vista do exposto, demonstra-se que o resgaste de valores da cultura humanista, tanto por parte dos trabalhos desenvolvidos pelas Nações Unidas, quanto pela AMF, é um caminho que está sendo traçado para a emersão de uma sociedade de paz que seja corretamente desenvolvida a partir de valores substanciais. A aquisição cotidiana de bons valores e costumes faz emergir, portanto, o conceito de cidadania, que recorre, mesmo sem que percebamos, aos valores do humanismo. Ou seja, a partir da educação, se cria uma cultura em que o homem se torna protagonista responsável de ações que gerem um impacto maior. E estas ações, que são oriundas de valores substanciais, levam à concretização do homem como 
um cidadão, mas aquele que não mede esforços para ir além, mostrar um resultado de abrangência mais significativa.

Os fundadores da UNESCO, em 1945, no momento em que resolveram criar um organismo para a cooperação internacional na área da educação, da cultura e da ciência, pretendiam criar uma cultura de paz. Para isso é preciso trabalhar nessas áreas para melhorar a compreensão entre os povos. Uma boa compreensão permite desenvolver e cultivar uma ética individual e essa ética individual com certeza se transformará num momento de cidadania (ABO, 2011, p. 28).

Pautar-se na lógica da Cultura Humanista faz com que a instituição se destaque por evidenciar um método também desenvolvido pelas Nações Unidas. A formação centrada no ser humano como pessoa incentiva uma forma de educar que possui como alicerce a apropriação de conhecimentos que tornem o jovem um agente de mudanças, apto a mostrar resultados práticos e positivos na dinâmica da vida, concretizando, assim, o real conceito de ser humano na esfera da cidadania. Segundo palavras da Dra. Estela Giordani:

\begin{abstract}
A pedagogia aplicada nos centros de formação humanista forma jovens que têm a coragem e a humildade de afrontar a si mesmos, e isso os faz dignos, confiantes e preparados para serem respostas eficientes para si e para todo o composto social em que se inserem, tornando-se sementes da vida e produzindo frutos maravilhosos. São verdadeiros fermentos de transformação social; são capazes de, com ordem, inteligência e técnica, afrontarem problemáticas sociais com excelentes resoluções. Com eles, temos a garantia do futuro do projeto humano (ABO, 2011, p. 91).
\end{abstract}

Desta forma, o aprendizado de atitudes e valores substanciais é uma dimensão que deve ser, cada vez mais, colocada em destaque. Pensando nisso, a Antonio Meneghetti Faculdade não reduziu essa dimensão apenas nas considerações humanistas. A instituição tornou possível reconhecer a palavra sustentabilidade - também proposta pelas Nações Unidas - e seus belos resultados em suas práticas e trabalhos.

A palavra sustentabilidade faz referência a ações responsáveis e atitudes humanas que visam suprir às necessidades atuais dos seres humanos, sem que o futuro das próximas gerações seja comprometido. Ou seja, está intrinsicamente relacionada a ações inteligentes e pontuais que resultem em um desenvolvimento pleno e sustentável da sociedade. Tudo começa no indivíduo, a ação singular de um sujeito que, de forma natural, se expande e faz reação frente ao social. Desta reação, mais e mais sujeitos passam a aderir novas formas práticas sustentáveis de ações, nascendo, portanto, uma consciência superior, maior e de grande alcance: aquela de nível global.

A contribuição da educação para o desenvolvimento sustentável, e para a consequente cidadania global, é um valor que transforma o modo como as pessoas pensam e agem coletivamente, pois além destas novas metodologias de ensino e estratégias contribuírem para 
a desconstrução de princípios carentes em resultados, há o reforço da democracia, a concretização de direitos fundamentais e a formação de cidadãos glocais ${ }^{3}$.

\title{
2.2 A concretização de uma pedagogia que vai ao encontro da formação de cidadãos globais
}

O verbo "oportunizar", que significa oferecer meios ou condições para que algo se realize (Dicionário online de Português, 2018) e possua um resultado efetivo, é uma palavra que descreve plenamente os trabalhos desenvolvidos pela Antonio Meneghetti Faculdade. Segundo palavras da Diretora da instituição,

\begin{abstract}
A Antonio Meneghetti Faculdade proporciona ao aluno experimentar-se dentro de uma dinâmica entre teoria e prática que o leva à evolução existencial, cultural, material e científica. Os professores da AMF são profissionais com experiência interdisciplinar e cultivam como valor da educação o ensinar os estudantes a buscarem respostas inteligentes para os seus anseios nas esferas profissional, pessoal, social e familiar (BIASOTTO, 2018).
\end{abstract}

Ao realizarmos uma simples interpretação de suas palavras, percebe-se, de fato, que a instituição oportuniza ao aluno, por meio da arte de educar, aprender a interpretar a dinâmica da vida, ou seja, a como se posicionar frente às diversas situações cotidianas. Há, também, uma certa cultivação de valores que não somente se restringem ao técnico. A instituição proporciona um olhar que vai além, um olhar cauteloso e de bom juízo que é capaz de ensinar ao jovem a como desenvolver resultados e ações positivas no meio em que está inserido, de forma que suas respostas frente às demandas sociais e acontecimentos cotidianos sejam efetivas. E respostas inteligentes são sinônimo de uma sociedade que prospera, cresce e evolui.

Desenvolvendo suas atividades pedagógicas a partir de pilares que sustentam a ideia de que resultados de aprendizagem efetivos e relevantes somente podem ser alcançados por meio da oferta de ensino de qualidade e de processos pedagógicos que permitam aos alunos adquirir competências, habilidades e conhecimentos relevantes (Grupo Redator, 2018, p. 13), a instituição vem concretizando suas forças no que tange ao implemento de propostas inovadoras que norteiam o desenvolvimento humano e sustentável a nível global, por meio de

\footnotetext{
3 "Cidadãos glocais" é um termo proposto pelas Nações Unidas que faz referência àqueles cidadãos que se sentem preocupados com temáticas que norteiam o trabalho de desenvolvimento social e, para tanto, agem localmente, em sua cidade, bairro, escola, etc., propondo soluções ou discutindo sobre temáticas apresentadas pela ONU, de modo a visar um impacto sustentável mais significativo, ou seja, de maior abrangência.
} 
ações que são alinhadas à Pedagogia Ontopsicológica e, em paralelo, aos Objetivos de Desenvolvimento Sustentáveis, propostos pelas Nações Unidas.

A instituição afirma, desta maneira, a concretização da formação de uma inteligência diferenciada. A interdisciplinaridade, sustentadora dessas diferentes metodologias, propõe a abrangência de diferentes formas de agregar conhecimentos e saberes que, de certo, contemplam ações práticas de grande valor ao social. E, conforme exposto alhures, a aquisição cotidiana de bons valores e costumes faz emergir o conceito de cidadania. E esse conceito não mais se demonstra como vago a partir do momento em que se tem uma formação que abranja temáticas que façam jus ao verbo "ser", acompanhado da palavra "cidadão".

Ser cidadão, na medida da existência, é, portanto, possuir um olhar múltiplo para saber identificar as tantas deficiências que se sucedem diariamente no social. Mas, para além disso, é saber fazer um juízo competente que leve a ações coerentes e de uma abrangência maior. E falar na expansão da abrangência desses atos positivos na sociedade em que o homem está inserido, é poder propor, finalmente, o conceito de cidadania global.

Mais do que apenas realizar ações locais e pontuais, ser cidadão global significa impulsionar um novo modelo de cidadania, aquela ativamente comprometida ao objetivo de alcançar um mundo mais igualitário e sustentável. O conceito envolve o entendimento de que todas as pessoas pertencem a uma raça, a humana, e que quem carrega esse conceito deseja um mundo sustentável, pacífico e justo (MOREIRA, 2018).

A proposição de temáticas que abrangem a discussão de questões globais em diferentes palestras, simpósios e congressos promovidos pela $\mathrm{AMF}$ propicia à comunidade $\mathrm{e}$ aos alunos o conhecimento de diferentes objetos de estudo que norteiam o desenvolvimento sustentável, de forma a contribuir para que novas ações práticas de valor sejam pensadas. Ou seja, a formação dos alunos da Antonio Meneghetti Faculdade, por meio da interdisciplinaridade abrangida, faz possível a formação de cidadãos de consciência global.

\subsection{A oportunidade de uma educação superior enquanto alcance de um direito fundamental}

A educação costuma figurar-se como um dos clamores de natureza social mais significativos no sentido de transformação e melhoria da vida humana (PESSANHA, 2018). Dentro do rol dos direitos humanos fundamentais encontra-se o direito à educação, podendo ser afirmado como um bem necessário para um próspero desenvolvimento do social. Mas, não só: além de ser um valor que alcança o patamar de direito fundamental, também se faz 
presente dentro do sistema jurídico brasileiro, amparado por normas nacionais e internacionais.

Importante salientar, em parâmetro nacional, as abordagens referentes à educação que se fazem presentes no texto constitucional brasileiro. Mesmo tendo sua promulgação no ano de 1988, há exatos 30 anos, a Constituição da República Federativa do Brasil já demonstrava, em suas redações, o merecimento da seguridade à educação aos cidadãos nacionais, conforme disposições de seu artigo 205:

A educação, direito de todos e dever do Estado e da família, será promovida e incentivada com a colaboração da sociedade, visando ao pleno desenvolvimento da pessoa, seu preparo para o exercício da cidadania e sua qualificação para o trabalho (BRASIL, 1988).

Cumpre lançarmos olhos para o ocorrido no ano de 1993, em âmbito mundial: a educação passou a ser considerada componente fundamental dos direitos humanos. Neste ano, a temática da Educação em Direitos Humanos foi debatida na Conferência Mundial sobre Direitos Humanos, realizada em Viena, na Áustria. A partir do documento resultante Declaração de Viena -, mostrou-se evidente a importância da educação como pressuposto fundamental para a compreensão dos demais direitos humanos (MARIALVA, 2018):

80. A educação em matéria de Direitos Humanos deverá incluir a paz, a democracia, o desenvolvimento e a justiça social, conforme definidos nos instrumentos internacionais e regionais de Direitos Humanos, a fim de alcançar uma compreensão e uma consciencialização comuns, que permitam reforçar o compromisso universal em favor dos Direitos Humanos (Declaração e Programa de Ação de Viena, 1993).

Em 16 de dezembro de 1966, a Assembleia Geral das Nações Unidas adotou como pauta de seu discurso o "Pacto Internacional dos Direitos Econômicos, Sociais e Culturais". Dentro do pilar dos direitos sociais, a temática "educação" foi expressamente abordada como um direito inerente à pessoa humana, ao passo de capacitar crianças e adultos para uma sociedade efetivamente desenvolvida. Nesse sentido, cumpre correlacionar o art. $13, \S 1^{\circ}$, do Pacto:

Os Estados-partes no presente Pacto reconhecem o direito de toda pessoa à educação. Concordam em que a educação deverá visar ao pleno desenvolvimento da personalidade humana e do sentido de sua dignidade e a fortalecer o respeito pelos direitos humanos e liberdades fundamentais. Concordam ainda que a educação deverá capacitar todas as pessoas a participar efetivamente de uma sociedade livre, favorecer a compreensão, a tolerância e a amizade entre todas as nações e entre todos os grupos raciais, étnicos ou religiosos e promover as atividades das Nações Unidas em prol da manutenção da paz (Pacto Internacional dos Direitos Econômicos, Sociais e Culturais, 1966). 
Em outras palavras, ao falarmos de educação, falamos também de um direito fundamental, porque inclui um processo de desenvolvimento individual próprio à condição humana (Instituto Latino-Americano da ONU para a Prevenção do Delito e Tratamento do Delinquente, 2018). Contudo, para além dessa perspectiva individual, esse direito deve ser visto, sobretudo, de forma coletiva, como um direito social, um direito a uma política educacional, em paralelo a ações afirmativas. Mas, afinal, o que seriam esses "direitos sociais"?

Os direitos sociais são, na melhor definição do Pacto Internacional de Direitos Econômicos, Sociais e Culturais aqueles que visam garantir aos indivíduos o exercício e usufruto de direitos fundamentais, em condições de igualdade, para que tenham uma vida digna, por meio da proteção e garantias dadas pelo Estado Democrático de Direito (PEREIRA, 2018).

Sob essas argumentações, anuncia-se o direito a educação como um modo de alcance aos direitos fundamentais, não esquecendo que a proteção desse direito deve ser salvaguardada pelo Estado. Mas, evidencia-se, também, em modo prático, a presença de instituições privadas que norteiam a garantia desse direito, ao colaborarem para um sistema democrático de forma efetiva: oportunizando a educação para tantos jovens e adultos que fazem parte do sistema social.

Sob esse ângulo, é imprescindível pautar o trabalho pedagógico desenvolvido pela Antonio Meneghetti Faculdade como um grande colaborador para o alcance de um direito fundamental. A oportunidade de uma educação superior proposta pela instituição, em que é perceptível a relevância e pertinência da aplicabilidade de um sistema de ensino efetivo, vai ao encontro de um bem social. E o desenvolvimento de uma pedagogia diferenciada, alicerçada em propostas e princípios pautados pelas Nações Unidas, e que se substanciam em valores efetivos, apenas tende a ampliar essa concretização.

\section{Metodologia}

A pesquisa que originou este artigo sustentou-se em análises fundamentadas acerca de temáticas propostas pelas Nações Unidas, em paralelo aos trabalhos pedagógicos desenvolvidos pela Antonio Meneghetti Faculdade, mais precisamente pela escola de Pedagogia Ontopsicológica. Esse trabalho possui, portanto, cunho bibliográfico por consistirse em uma discussão teórica acerca da temática abordada. 


\section{Considerações finais}

Ao findar este trabalho, a evidência de que a arte de educar é tão antiga quanto as raízes da palavra sociedade se fez clara, mas o fato de que ambas estão em constante desenvolvimento e que o progresso e a concessão de novas formas de pensar e agir é necessária, também. Por esse motivo, identificamos ser necessário promover um modelo de educação que compreenda um conhecimento capaz de colher os problemas globais (FUNDAÇÃO ANTONIO MENEGHETTI, 2017, p. 39). É necessário um ensino que disponibilize métodos que permitam levar a resultados efetivos. E a Antonio Meneghetti Faculdade vai ao encontro da concretização dessas exigências.

Fortalecer-se enquanto setor privado que possui um compromisso frente ao desenvolvimento sustentável e à formação de seres humanos, por meio da educação, é, portanto, um oportuno trabalho a ser feito constantemente, que possui um alto nível de responsabilidade. E pautar temáticas que norteiam a aplicação de metodologias propostas pelas Nações Unidas é resultado do desenvolvimento de uma inteligência superior.

Na Antonio Meneghetti Faculdade, os jovens são educados a partir de um modelo de conhecimento em que a condição humana é objeto essencial de ensino, um modelo de racionalidade que diz respeito à existência: ao homem e a sua existência, ao homem e o seu mundo, ao homem e a sua sociedade (FUNDAÇÃO ANTONIO MENEGHETTI, 2017, p. 249). A Ontopsicologia permite desenvolver uma formação global e integral do ser, o que propicia o valor da dignidade do indivíduo. A Pedagogia Ontopsicológica tem o objetivo de formar o homem pessoa na função social, que irá lhe proporcionar saber lidar com os ditames sociais que afrontam a realidade em que ele vive, de forma a gerar resultados efetivos. Ou seja, a disposição de diferentes metodologias que abrangem um grau maior de eficiência se faz presente na instituição, além do resgaste da cultura humanista e do conceito de sustentabilidade, que são dois fundamentos pautados como grandiosos para o desenvolvimento da civilização e do progresso social.

Além desses aportes, a Antonio Meneghetti Faculdade oportuniza a diversos jovens e adultos a fruir de um direito fundamental existente no âmbito social: o direito à educação. Dessa forma, mostra à sociedade que instituições privadas também podem ser protagonistas responsáveis ao colaborar para a efetividade de direitos que, muitas vezes, passam por despercebidos. 
Em síntese, a Antonio Meneghetti Faculdade acredita que, de fato, o mundo está cheio de indivíduos inteligentes que fazem todo o gênero de coisas inteligentes, de forma a proporcionar oportunidades de crescimento para que o "acontecer" se faça presente (MENEGHETTI, 2014, p. 25). Ela trabalha o homem, ser, pessoa, em prol da construção de uma inteligência superior que faça acontecer uma sociedade humanista, mais próspera e global. Sua pedagogia de ensino é propositiva de valores para a sociedade, visando preparar homens aptos a resolver suas constantes demandas em contínua evolução (AMF, 2018). A instituição parte do princípio que o sucesso ou insucesso dos resultados futuros dependem somente da precisão da formulação do vetor de formação dos estudantes, hoje (TSVETKOVA, 2018).

Constata-se, para tanto, que a pedagogia educacional desenvolvida na Antonio Meneghetti Faculdade concretiza-se como formadora de jovens protagonistas responsáveis, capazes de serem gestores de impactos na sociedade em que vivem, ao passo de tornar realidade uma meta das Nações Unidas: mais do que apenas realizar ações locais e pontuais, contribuir para o aumento de cidadãos globais, cidadãos que possuem a conscientização da necessidade de enfrentar com mais veemência os problemas da humanidade.

\section{Referências}

Associação Brasileira de Ontopsicologia (ABO). Identidade Jovem: A Formação Humanista de Jovens como garantia de Sustentabilidade, Identidade e Protagonismo Civil. Recanto Maestro: Associação Brasileira de Ontopsicologia, 2011./PRONAC nº 098244.

Antonio Meneghetti Faculdade. Foco no Desenvolvimento Humano - Valores institucionais. Disponível em: https://faculdadeam.edu.br/amf/institucional $>$ Acesso em: 28 de setembro de 2018.

BIASOTTO, Helena. Carta da Direção. Disponível em: $<$ https://faculdadeam.edu.br/amf/institucional $>$ Acesso em: 15 de outubro de 2018.

BRASIL. Constituição da República Federativa do Brasil: texto constitucional promulgado em 5 de outubro de 1988, com as alterações determinadas pelas Emendas Constitucionais de Revisão nos 1 a 6/94, pelas Emendas Constitucionais nos 1/92 a 91/2016 e pelo Decreto Legislativo no 186/2008. - Brasília: Senado Federal, Coordenação de Edições Técnicas, 2016.

DELORS, Jacques. Educação: um tesouro a descobrir. São Paulo: Cortez. Brasília, DF: MEC/UNESCO, 2003.

Dicionário Online de Português. Disponível em: $<$ https://www.dicio.com.br/ $>$ Acesso em: 15 de outubro de 2018. 
Fundação Antonio Meneghetti. Ontopsicologia: Ciência Interdisciplinar - Volume III. Recanto Maestro, São João do Polêsine, RS: Fundação Antonio Meneghetti, 2017. 400 p.

Grupo Redator. Educação 2030: Declaração de Incheon e Marco de Ação da Educação. Disponível em: <http://unesdoc.unesco.org/images/0024/002432/243278POR.pdf> Acesso em: 22 de outubro de 2018.

Instituto Latino-Americano da ONU para a Prevenção do Delito e Tratamento do Delinquente. $O$ direito à educação: garantias legais. Disponível em: http://fundacaotelefonica.org.br/promenino/trabalhoinfantil/dca/o-direito-a-educacaogarantias-legais/> Acesso em: 30 de outubro de 2018.

MARIALVA, Alexandre. O Brasil, a educação e os tratados internacionais. Disponível em: $\quad<$ http://observaeduca.blogspot.com/2012/01/o-brasil-educacao-e-os-tratados.html> Acesso em: 25 de novembro de 2018.

MENEGHETTI, Antonio. Do humanismo histórico ao humanismo perene; Tradução: Ontopsicológica Editora Universitária, $2^{\mathrm{a}}$ edição. Recanto Maestro: Ontopsicológica Editora Universitária, 2014.

Michaelis: Dicionário Brasileiro de Língua Portuguesa. Disponível em: $<$ https://michaelis.uol.com.br> Acesso em: 28 de setembro de 2018.

MOREIRA, Danilo. Você já ouviu falar em cidadania global? Saiba mais sobre essa corrente. Disponível em: <https://www.geniocriador.com.br/blog-genio/130-voce-ja-ouviufalar-em-cidadania-global-saiba-mais-sobre-essa-corrente $>$ Acesso em: 10 de outubro de 2018.

Nações Unidas. Objetivo 4: Assegurar a educação inclusiva e equitativa e de qualidade, e promover oportunidades de aprendizagem ao longo da vida para todas e todos. Disponível em: <https://nacoesunidas.org/pos2015/ods4/> Acesso em: 21 de outubro de 2018.

Pacto Internacional dos Direitos Econômicos, Sociais e Culturais. Disponível em: $<$ http://www.oas.org/dil/port/1966\%20Pacto\%20Internacional\%20sobre\%20os\%20Direitos\% 20Econ $\%$ C3\%B3micos, $\% 20$ Sociais $\% 20 \mathrm{e} \% 20$ Culturais.pdf $>$ Acesso em: 28 de outubro de 2018.

PEREIRA, Uanderson. A Efetividade dos direitos sociais: o direito à moradia. Disponível em: $\quad<$ http://www.puc-rio.br/pibic/relatorio_resumo2015/resumos_pdf/ccs/DIR/JUR3382_Uanderson\%20Pereira.pdf> Acesso em: 29 de outubro de 2018.

PESSANHA, Vanessa Vieira. Um panorama do direito fundamental à educação na Constituição Federal de 1988. Disponível em: <https://jus.com.br/artigos/24050/umpanorama-do-direito-fundamental-a-educacao-na-constituicao-federal-de-1988> Acesso em: 28 de outubro de 2018 .

Portal de Direito Internacional. Declaração e Programa de Ação de Viena: Conferência Mundial sobre Direitos Humanos. Disponível em: $<$ http://www.oas.org/dil/port/1993\%20Declara\%C3\%A7\%C3\%A3o\%20e\%20Programa\%20d e $\% 20 \mathrm{Ac} \% \mathrm{C} 3 \% \mathrm{~A} 7 \% \mathrm{C} 3 \%$ A3o\%20adoptado\%20pela\%20Confer $\% \mathrm{C} 3 \%$ AAncia $\% 20$ Mundial $\%$ 
20de $\% 20$ Viena $\% 20$ sobre $\% 20$ Direitos\%20Humanos\%20em $\% 20$ junho\%20de $\% 201993 . p d f>$ Acesso em: 25 de novembro de 2018.

SCOTTINI, Alfredo. Dicionário Escolar da Língua Portuguesa. Blumenau, SC: Todolivro Editora, 2009.

TSVETKOVA, Larissa. Uma pedagogia para o futuro. Disponível em: $<$ https://reciprocidade.emnuvens.com.br/novapedagogia/article/viewFile/131/152> Acesso em: 18 de outubro de 2018. 